\title{
LIBRARY 4.0: ECO-BLENDED LIBRARY AND LIBRARY INCLUSION
}

\author{
Rozikin Mochammad*, Rindi Ardika MS**, \& Teguh Yudi \\ Cahyono***
}

*Fakultas Ilmu Administrasi Universitas Brawijaya

**Pascasarjana Fakultas Ilmu Adminitrasi Universitas Brawijaya

**Pascasarjana Fakultas Ilmu Adminitrasi Universitas Brawijaya

Email:mochrozikin@ub.ac.id

(Submitted: 15-12-2019, Revised: 14-04-2020, Accepted: 12-11-2020)

DOI: $10.24252 /$ kah.v8i2a2

\begin{abstract}
ABSTRAK: Perpustakaan sebagai perangkat vital di dunia pendidikan hari ini diarahkan untuk menerapkan digitalisasi, yang disebut library 4.0. Untuk mempertahankan eksistensi perpustakaan, diperlukan adanya inovasi pelayanan yang mampu menjangkau kebutuhan generasi digital native. Inovasi pelayanan perpustakaan di Universitas Negeri Malang, dalam upaya menciptakan ekosistem Library 4.0 telah berhasil menerapkan inovasi-inovasi. Inovasi tersebut berupa program Eco-Blended Library seperti kebun E-book, Beringin Baca, playground anak-anak, café pustaka, pentas seni, movie talk, dan lapak diskusi. Selain itu juga mampu mengembangkan perpustakaan berbasis inklusi dengan adanya fasilitas Sistem Informasi Pustaka Terpadu (SIPADU) digitalisasi koleksi bekerjasama dengan Indonesia OneSearch, layanan chat reference, peminjaman dan perpanjangan online, serta literasi informasi. Ke depan, perpustakaan Universitas Negeri Malang perlu untuk meningkatkan jumlah sumber daya manusia yang fokus dalam layanan digital library, semakin mendorong sumber daya manusia untuk melakukan publikasi ilmiah online dan mengikuti forum atau kelompok pelatihan online.
\end{abstract}

Kata kunci: Inovasi perpustakaan; Perpustakaan 4.0; Perpustakaan Eco-Blanded; Perpustakaan berbasis inklusi

ABSTRACT: The role of libraries in education today is directed at implementing digitization, called Library 4.0. There is a need for service innovation that is able to reach the needs of the digital natives. This study describes and analyzes the innovation of Library Services 4.0: EcoBlended Libraries and Inclusion-Based Library at Universitas Negeri Malang's Library. This research uses descriptive qualitative method. The data were obtained through interviews with librarians, observation and documentation. The results showed that in an effort to create a library ecosystem 4.0, the library has succeeded in implementing innovations. These innovations are in the form of an Eco-Blended Library program such as an E-book garden, Beringin Baca, a children's playground, a library café, art performances, movie talk, and discussion booths. In addition, inclusion-based library is also developed with the Integrated Library Information System (SIPADU) facility digitizing collections in collaboration with Indonesia OneSearch, chat reference services, online loan and extension library collections, as well as information literacy. As a suggestion, the library needs to increase the number of human resources who might more focus on digital library services, further encouraging human resources to conduct online scientific publications and participate in online training forums or groups.

Keywords: Library innovation; Library 4.0; Eco-Blanded library; Library inclusion

\section{PENDAHULUAN}

Pendidikan di era 4.0 tertuntut untuk mengikuti pengembangan digital di dalam manajemennya (Jalil, 2015). Termasuk perpustakaan sebagai perangkat vital di dunia 
pendidikan, juga diarahkan untuk menerapkan digitalisasi, yang disebut library 4.0. Selama ini dengan berkembangnya Internet of Things, perilaku pemustaka berubah menjadi karakter khas generasi digital native, yang memiliki ciri-ciri seperti: (a) Mengandalkan kecepatan dalam menyerap informasi; (b) Kebutuhan multitasking; (c) Lebih menyukai gambar daripada teks; (d) Menyukai media sosial dan kolaborasi; (e) Teknologi sebagai bagian dari hidupnya, tidak nyaman jika tidak menggunakan teknologi (seperti telepon pintar dan internet); (f) menyukai hal yang instan, dan hal terkait dengan teknologi informasi (Istiana, 2016).

Perpustakaan yang masih menjalankan sistem secara manual dan konvensional, dan tidak mampu beradaptasi menyesuaikan dengan kebutuhan generasi digital native, diprediksi akan mengalami kematian (Cribb, 2018). Untuk itu diperlukan adanya inovasi pelayanan yang mampu menjangkau kebutuhan generasi digital native. Inovasi merupakan prinsip utama untuk menjalankan organisasi publik, inovasi adalah kunci sukses suatu organisasi dapat tetap bertahan dan berkelanjutan (sustainable) menghadapi segala macam perubahan serta merupakan kunci pengukuran kinerja suatu organisasi publik (Hidayah, 2018).

Penelitian tentang inovasi perpustakaan pada era Library 4.0 selama ini hanya meneliti urgensi inovasi dan digitalisasi, belum banyak yang meneliti tentang implementasi inovasi di era 4.0 (Rhoni, 2019; Rodhin, 2019; Sari, 2019). oleh karena itu dalam penelitian ini akan mengulas bagaimana implementasi inovasi di lapangan. Inovasi perpustakaan diharapkan berbasis inklusi, dimana istilah inklusif memiliki ukuran universal. Istilah inklusif dapat dikaitkan dengan persamaan, keadilan, dan hak individual dalam pembagian sumber-sumber seperti politik, pendidikan, sosial dan ekonomi. Menurut Gavin, masing-masing dari aspek-aspek tersebut tidak berdiri sendiri, melainkan saling berkaitan satu sama lain. Gavin menyatakan bahwa istilah inklusif berkaitan dengan banyak aspek hidup manusia yang didasarkan atas prinsip persamaan, keadilan dan hak individu (Gavin, 2005). Lebih dari itu masyarakat sudah sangat terbuka dengan TI sehingga inklusi tidak terhindarkan, terlebih dalam pelayanan perpustakaan yang beragam latar belakang penggunanya serta ada yang berkebutuhan khusus.

Sejalan itu, dengan adanya program yang dicanangkan oleh Bappenas dan Perpustakaan Nasional RI terkait upaya pengentasan kemiskinan dengan peningkatan literasi masyarakat, dikembangkan suatu model pengembangan perpustakaan berbasis inklusi sosial. Sebagaimana dijelaskan oleh (NS, 2008) yang menyatakan bahwa perpustakaan mengemban misi untuk menanamkan pengertian dan pemahaman yang utuh dan lengkap tentang pentingnya penguasaan informasi, ilmu pengetahuan, dan teknologi. Untuk itulah perpustakaan diharapkan dapat bertransformasi dengan mengoptimalkan peran dan fungsinya sebagai pusat belajar sepanjang hayat dan sebagai wadah untuk kegiatan masyarakat melalui pendampingan sehingga dapat meningkatkan kualitas hidup dan kesejahteraan masyarakat secara terbuka, transparan.

Fokus penelitian ini adalah tentang keberhasilan penerapan inovasi di sektor publik, studi pada inovasi pelayanan perpustakaan yang diterapkan di perpustakaan Universitas Negeri Malang (UM), khususnya dalam upaya menciptakan ekosistem Library 4.0 yaitu sistem perpustakaan berbasis lingkungan dengan digitalisasi teknologi dengan menerapkan Perpustakaan Berbasis Inklusi dan Eco-Blended Library. Sudah menjadi rahasia umum bahwa berbagai perpustakaan di seluruh Indonesia berupaya mewujudkan konsep perpustakaan berinklusi sosial. Dalam konsep yang masih bersifat wacana dan berupa perencanaan tersebut, perpustakaan Universitas Negeri Malang sudah menerapkan konsep perpustakaan berbasis inklusi sosial tersebut serta inovasi lain, sehingga dapat digunakan sebagai benchmark untuk perguruan-perguruan tinggi lain yang belum menerapkan. Tulisan ini juga mendeskripsikan faktor-faktor layanan penerapan Library 4.0 yang terpenuhi dari inovasi-inovasi yang dijalankan dan faktor-faktor yang tidak terpenuhi beserta hambatannya.

\section{KAJIAN TERDAHULU}

Perpustakaan sebagai pelayanan publik perlu meningkatkan kualitas secara berkelanjutan. "Service quality is the extent of discrepancy between customer's expectations or desires and their perceptions" (Zeithaml, 1990). Kualitas layanan adalah sesuatu yang berhubungan dengan 
terpenuhinya harapan/kebutuhan pelanggan, dimana layanan dikatakan berkualitas apabila dapat menyediakan produk dan jasa (layanan) sesuai dengan kebutuhan dan harapan pelanggan. Dalam hal ini, kualitas pada dasarnya terkait dengan layanan yang baik, yaitu sikap atau cara karyawan dalam melayani pelanggan atau masyarakat secara memuaskan (Goetsch dan Davis, 2000.

Salah satu upaya peningkatan kualitas layanan publik adalah dengan inovasi. Inovasi merupakan suatu ide, praktik, atau objek yang dirasakan seperti baru oleh seorang individu (Osborne, 2002). Terdapat beberapa bentuk jenis dan indikator inovasi, menurut Suwarno (2008) inovasi adalah: (a) Pengetahuan baru, (b) Cara Baru, (c) Objek Baru, (d) Teknologi Baru, dan (e) Penemuan Baru. Mulgan dan Albury (2003) membagi jenis inovasi ke dalam 3 macam yakni: (a) Inovasi radikal, (b) Inovasi inkremental, dan (c) Inovasi Transformatif: Inovasi sistemis dengan perubahan dalam struktur angkatan kerja dan organisasi mengubah semua sektor hingga sistem organisasi. Inovasi biasanya erat kaitannya dengan lingkungan yang berkarakteristik dinamis dan berkembang (Robbins, 1994). Menurut UU No. 18 tahun 2002 Inovasi adalah kegiatan penelitian, pengembangan, dan/atau perekayasaan yang bertujuan mengembangkan penerapan praktis nilai dan konteks ilmu pengetahuan yang baru, atau cara baru untuk menerapkan ilmu pengetahuan dan teknologi yang telah ada ke dalam produk atau proses produksi.

Penelitian sebelumnya menunjukkan pentingnya perpustakaan di era disrupsi 4.0 untuk melakukan inovasi dengan menerapkan artificial intelligence (Sari, 2019). Disrupsi ini terjadi di berbagai macam perpustakaan baik itu perguruan tinggi negeri, swasta dan Islam, digitalisasi koleksi, open access, kerjasama antar perpustakaan, continues improvement untuk pustakawan menjadi serangkaian inovasi yang penting (Rhoni, 2019; Rodhin, 2019). Inovasi yang dilakukan di berbagai negara untuk adaptasi ke perpustakaan modern mengusung sustainable library yakni dengan menciptakan green library seperti pada India, Kenya, ukraina, Jerman, Kroasia, Kolombia (Hauke, 2015; Hauke, Grunwald, \& Wilde, 2014; Meher \& Parabhoi, 2017).

Pengembangan inovasi pada organisasi (baik publik, privat maupun masyarakat), akan diikuti perubahan setidaknya meliputi 6 karakter, yakni (Erawati Djamrut, 2015): (a) Penggantian (substitution), misalnya penggantian jenis perpustakaan, penggantian bentuk perabotan; (b) Perubahan (alternation), meliputi perubahan sistem, cara kerja, dan teknologi yang digunakan dengan sesuatu yang baru. Hal ini diikuti perubahan tugas pustakawan dari pelayanan offline ke online. Juga perubahan metode meminjam buku dari manual berubah menjadi peminjaman buku online melalui digital library; (c) Penambahan (addition); (d) Penyusunan kembali (restructuring), struktur, tata kerja, dan sistem yang digunakan dengan mengadopsi inovasi sehingga lebih mudah diterapkan; (e) Penghapusan (elimination), seperti upaya menghapus daftar hadir manual melalui buku kunjung perpustakaan dengan inovasi online member card scanner; dan (f) Penguatan (reinforcement).

Selain terbentuknya inovasi dengan berbagai jenis, dalam kenyataan lapangan seringkali inovasi tidak berjalan secara optimal atau bahkan gagal, beberapa faktor penentu dan penghambat inovasi adalah sebagai berikut (Ibrahim, 1998): (a) Estimasi yang tidak tepat terhadap inovasi; (b) Konflik dan motivasi; (c) Inovasi tidak berkembang; (d) Masalah keuangan; (e) Penolakan inovasi dari kelompok tertentu; dan (f) Kurang adanya hubungan sosial. Selain faktor tersebut penelitian sebelumnya menyebutkan dalam era disrupsi profesi khususnya di bidang perpustakaan, hambatan dalam menerapkan Library 4.0 adalah kompetensi pustakawan dalam melakukan transformasi serta kemauan/optimisme untuk menghadapi tantangan dan peluang masa depan (Nashihuddin, 2018).

Tidak banyak referensi terkait perpustakaan era 4.0. Konsep ini adalah sebuah konsep perpustakaan yang baru. Meskipun begitu beberapa tahun terakhir telah banyak seminar dan gagasan yang dikeluarkan mengenai konsep ini, beberapa gagasan mengenai perpustakaan 4.0 telah menghasilkan indikator-indikator perpustakaan era 4.0 yakni sebagai berikut (Noh, 2015; Shaleh, 2005; Maryani, 2016): (a) Intelligence makerspace: Inovasi ruang dan sarana prasarana dilengkapi TI yang berada di dalam satu lokasi dan dapat diakses secara bebas serta mandiri 
untuk berkreasi dan berinovasi; (b) Open source: Penyediaan koleksi online yang dapat diakses oleh seluruh kalangan masyarakat yang bertujuan untuk meningkatkan penyempurnaan layanan kepada pengguna, memenuhi kebutuhan pengguna dan memberikan pengalaman yang menyenangkan kepada pengguna (User centric/user experience); (c) Big data: Pengelolaan data terpadu, penerapan sistem One Stop Searching atau sistem satu pintu untuk memudahkan user menikmati fasilitas yang disediakan perpustakaan secara cepat; (d) Cloud Computing: Penggabungan pemanfaatan teknologi komputer dan pengembangan berbasis internet. Sebagai metode komputasi dimana kapabilitas terkait teknologi informasi disajikan sebagai suatu layanan (as a service), sehingga pengguna dapat mengaksesnya lewat Internet (di dalam awan) tanpa mengetahui apa yang ada di dalamnya; (e) Augmented Reality: mendekatkan informasi kepada user, penyediaan katalog-katalog online yang dapat diakses oleh pemustaka sehingga pemustaka dapat lebih memahami koleksi yang dicari. beberapa cara mendekatkan informasi kepada user adalah (1) Memberi sumber informasi kilat (penyediaan mailist yang meliputi profesi tertentu untuk memberi informasi up-to-date dan akurat); (2) menjadi references bagi user; (3) Mengelola sosial media sebagai sarana tanya jawab, meminjam buku secara online; (4) web interaktif dengan mendesain situs web fasilitas 2 arah, berfungsi sebagai media sosial bagi pengguna, pemberian feedback atas pelayanan perpustakaan; (5) Menyediakan mobile library yang dapat diakses dimanapun; (f) State of the art: Pelayanan dan inovasi yang up to date yang dijalankan oleh perpustakaan sehingga pemustaka dapat menikmati pelayanan dari perpustakaan dan tidak akan bosan untuk memanfaatkan fasilitas dari perpustakaan; (g) Librarian 4.0 : harus terdukung oleh sumber daya manusia yang unggul. Pustakawan terus meng-upgrade kualitasnya melalui media online. menjadi anggota usenet, bergabung di lis-publibs atau menjadi anggota list-serv. Pustakawan juga dapat mendapatkan ilmu kepustakaan secara online melalui BUBL Information Service.

Penelitian sebelumnya menunjukkan salah satu manfaat dari Library 4.0 yang identik dengan digitalisasi dan TI, bermanfaat untuk menumbuhkan inklusifitas seperti yang diterapkan pada i-Jakarta (Noor, 2019). Olsen \& Fuller (2003) menegaskan bahwa inklusif merupakan sebuah terminologi yang secara umum digunakan untuk mendidik siswa baik yang memiliki maupun tidak memiliki disabilitas tertentu di dalam sebuah kelas regular. Sebagai perpustakaan di lingkungan pendidikan maka pelayanan berbasis inklusi adalah mengubah yang tereksklusikan menjadi terinklusi adalah dengan mengidentifikasi hambatan atau kesulitan yang dihadapi peserta didik dan mengupayakan sekolah umum/inklusif untuk dapat meningkatkan kemampuannya dalam mengatasi hambatan-hambatan tersebut agar dapat memenuhi kebutuhan mereka (Gavin, 2005). Dan melalui layanan Library 4.0 berbasis inklusi akan mampu mewujudkannya.

Perpustakaan yang ramah untuk semua, dengan pendekatan pendidikan yang berusaha menjangkau semua orang tanpa terkecuali. Semangat penyelenggaraan pendidikan inklusif adalah memberikan kesempatan atau akses yang seluas-luasnya kepada semua anak untuk memperoleh pendidikan yang bermutu dan sesuai dengan kebutuhan individu peserta didik tanpa diskriminasi. Untuk itu perpustakaan digital memberikan jawabannya (Herawati, dalam Shabarudin, 2017; Herviani dkk, 2018). Jalil (2015) menyatakan bahwa perpustakaan sebagai lingkungan merupakan lingkungan sosial masyarakat yang terbuka, ramah, meniadakan hambatan dan menyenangkan karena setiap warga masyarakat tanpa terkecuali saling menghargai dan merangkul setiap perbedaan.

\section{METODOLOGI PENELITIAN}

Desain penelitian yang digunakan penelitian ini kualitatif dengan metode deskriptif. Hal ini dimaksudkan untuk mendapatkan informasi mendalam dari fokus yang diteliti. Teknik pengumpulan data yang digunakan berupa wawancara, observasi dan dokumentasi. Teknik analisis data kualitatif yang digunakan model interaktif Miles, Huberman \& Saldana (2014). Model interaktif merupakan aktivitas dalam analisis data kualitatif yang dilakukan secara interaktif dan berlangsung secara terus-menerus sampai tuntas, sehingga datanya sudah jenuh. Proses analisis data melalui (a) data condentation (kondensasi data), (b) data display (penyajian 
data), dan (c) conclution drawing or verification (penarikan kesimpulan dan verifikasi). Lokasi Penelitian di Perpustakaan Universitas Negeri Malang, di Jl. Semarang nomor 5, Sumbersari, Kecamatan Lowokwaru, Kota Malang.

Penelitian ini dilakukan pada Bulan September-November 2019 dan dibatasi pada pencarian inovasi yang telah dilakukan. Di perpustakaan Universitas Negeri Malang banyak inovasi-inovasi yang masih dalam tahap perencanaan namun tidak dimasukkan dalam penelitian ini. Penentuan informan dilakukan dengan purposive (Cresswell, 2010), dan berkembang menjadi snowball di lapangan. Data yang disajikan ini berdasarkan hasil wawancara dengan 3 pustakawan Universitas Negeri Malang yang menangani di beberapa bidang inovasi yaitu penanggung jawab Kebun E-book dan eco-blended library. Juga 3 pengunjung/pengguna serta berdasarkan hasil observasi melalui website dan dokumen-dokumen yang dianggap relevan. Sedangkan untuk menguji validitas data, peneliti menggunakan teknik triangulasi.

\section{HASIL DAN PEMBAHASAN}

\section{Inovasi Layanan Perpustakaan Universitas Negeri Malang}

Strategi inovasi pelayanan perpustakaan Universitas Negeri Malang dalam rangka mewujudkan library 4.0 adalah terlihat seperti gambar berikut:

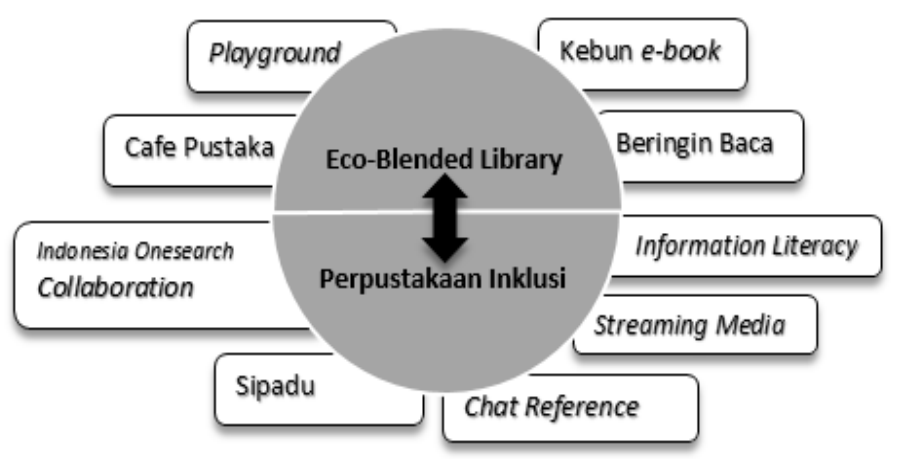

Gambar 1. Strategi Inovasi Perpustakaan Universitas Negeri Malang menuju library 4.0

\section{a) Eco-Blended Library}

Inovasi perpustakaan ini diilhami oleh sustainable development yang juga menjadi bagian pembangunan dan pengembangan Universitas Negeri Malang secara terintegrasi.

"Kami berorientasi kepada sustainable development (pembangunan berkelanjutan) dimana lingkungan menjadi bagian yang tidak dipisahkan dari perencanaan pemanfaatan ruang area yang ada. Atas dasar itu, perpustakaan Universitas Negeri Malang tidak lagi identik dengan bangunan kotak-kotak yang ada rak berisi buku-buku dan ruang baca yang berjajar meja dan kursinya" (Prof. Djoko Saryono, Kepala Perpustakaan Universitas Negeri Malang).

Perpustakaan Universitas Negeri Malang mencoba mengelola lingkungan alam sekitar yang ada dalam rangka mempertahankan ekosistem lingkungan di perpustakaan dengan memadukan lingkungan hijau tersebut dan pemanfaatan fasilitas perpustakaan. Hal ini dimaksudkan untuk memudahkan dan memuaskan pemustaka yang menginginkan konsep berkunjung ke perpustakaan dan memanfaatkan fasilitas perpustakaan secara outdoor. Sehingga dengan inovasi ini tujuannya adalah fungsi perpustakaan bukan hanya sebagai penyedia informasi. Akan tetapi juga menyediakan lahan untuk literasi informasi senyaman mungkin. Selain itu tujuannya untuk mendukung peran perpustakaan menjadi perpustakaan inklusif. Seperti yang disampaikan selanjutnya oleh Prof. Djoko Saryono: 
"Oleh karena itu kami berkeinginan perpustakaan dapat dimanfaatkan oleh siapa saja, dari kelompok mana saja bisa akses pelayanan perpustakaan, termasuk mereka yang berkebutuhan khusus dalam mendapatkan pelayanan pendidikan".

Pengakuan pengunjung mengenai fasilitas perpustakaan bisa menjadi objek wisata edukasi dengan penataan terintegrasi area dan gedung perpustakaan yang asri, udara segar dirasakan pengunjung dengan adanya Beringin Baca.

"Saya sangat kerasan di perpustakaan, suasananya enak, asri dan tidak membosankan sebab tata ruangnya tidak hanya tembok yang menyekat ruangan rak buku dengan tumpukan bukunya, tetapi sekarang penataannya banyak membuat pengunjung senang dan betah, ada ruang hijaunya, ada tamannya, ada cafénya, dan ruang bermain untuk anakanak, layanan manual dan online. kami rasa jika semua perpustakaan perguruan tinggi, perpustakaan pada umumnya tertata begini mungkin akan menjadi wisata edukasi. Berwisata sambil membaca literasi untuk mendapatkan informasi keilmuan" (Endro Kurniawan, mahasiswa semester 4).

Fasilitas dan layanan yang diberikan dalam eco-blended library adalah sebagai berikut:

\section{b) Beringin Baca}

Perpustakaan Universitas Negeri Malang memiliki pohon-pohon di luar gedung perpustakaan, termasuk pohon beringin besar yang menciptakan suasana yang teduh dan asri yang dimanfaatkan untuk duduk-duduk dan bersantai. Adanya pohon-pohon besar tersebut kadangkala menjadi suatu hambatan pembangunan dari suatu institusi sehingga seringkali ditebang dan dilakukan pembangunan untuk gedung fasilitas perguruan tinggi. Perpustakaan Universitas Negeri Malang justru memanfaatkan pohon besar tersebut sebagai media literasi yang nyaman bagi pemustaka. Pemustaka yang kesulitan atau bosan merasakan fasilitas perpustakaan yang bersifat indoor, mampu memanfaatkan area pohon beringin untuk membaca maupun aktivitas literasi dan belajar. Pohon ini dilengkapi sarana seperti stopkontak, Wi-Fi yang cepat, seringkali juga diadakan kegiatan rutin seperti bazar buku, pentas seni, lapak diskusi, movie talk. Kegiatan rutin ini diintegrasikan dengan fasilitas lain seperti café pustaka.

\section{c) Kebun E-book}

Kebun E-book adalah layanan perpustakaan dimana pemustaka dapat mengakses dan mengunduh e-book secara gratis dengan koneksi internet yang cepat. Perpustakaan berlangganan beberapa koleksi e-book untuk memenuhi kebutuhan koleksi pemustaka. Karena umumnya harga koleksi e-book sangatlah mahal. Sehingga perpustakaan berinisiatif untuk membuat Kebun $E$-book. Pemustaka dapat mengambil semua atau hanya beberapa koleksi $e$ book tanpa dipungut biaya. Dengan adanya Kebun E-book ini pemustaka tidak perlu membeli atau berlangganan artikel atau buku secara online, namun bisa mendapatkannya secara gratis dengan berkunjung ke Kebun E-book perpustakaan Universitas Negeri Malang selagi koleksi yang dicari tersedia. Diharapkan kebutuhan akan ilmu pengetahuan yang lebih up to date dapat terpenuhi dengan adanya koleksi e-book yang terdapat dalam layanan Kebun E-book perpustakaan.

"Semakin strategis peran perpustakaan untuk meningkatkan kualitas sumber daya manusia lewat literasi, dan sekarang ini para dosen sebagian besar sudah memanfaatkan internet dengan jurnal dan e-book. Mahasiwa banyak yang tidak bisa akses langsung sebab berbayar. Oleh karena itu perpustakaan Universitas Negeri Malang mengadakan dengan berlangganan dimana mahasiswa maupun dosen atau pengunjung bisa akses jurnal dan ebook tersebut dengan password tertentu tanpa bayar alias gratis. Dan itu kami namakan Kebun E-book". (Prof. Djoko Saryono)

Perkembangan perkuliahan sebagian besar dosen memanfaatkan kemajuan IT dengan memberikan tugas kepada mahasiswa untuk melacak literasi melalui e-book. Dalam proses pelacakan tersebut mahaiswa ada mengalami kesulitan yang berbiaya, harus membeli 
sedangkan kemampuan keuangan mahasiswa terbatas. Oleh karena itu perpustakaan Universitas Negeri Malang, mengadakan Kebun E-book sebagai jawaban atas permasalahan pendidikan.

\section{d) Playground anak-anak}

Konsep dari playground ini adalah digunakan untuk anak-anak (balita). Latar belakangnya adalah beragamnya pengunjung perpustakaan.

"Pengunjungnya beragam dari yang mahasiswa biasa yang masih bujang sampai mahasiswa doktoral yang sudah berkeluarga. Mereka berkunjung ke perpustakaan dengan membawa putra-putrinya. Juga ada beberpa dosen Universitas Negeri Malang yang berkunjung sebagai pengguna perpustakaan membawa keluarganya, termasuk putranya. Nah, dengan itu kami menyediakan tempat bermain anak-anak atau playground agar orangtuanya merasa nyaman belajar di perpustakaan tanpa terganggu oleh anaknya. Konsep inilah yang mengilhami dibangunnya playground ini" (Nurhakim Kepala Pengadaan, Pengolahan dan Pemeliharaan Koleksi).

Berdasarkan perkembangan dari pengguna perpustakaan yang beragam, maka dengan adanya fasilitas playground ini mereka dapat mengajak anak mereka ke perpustakaan dan menikmati pelayanan literasi perpustakaan tanpa terganggu dan kesulitan dengan adanya balita. Dengan kata lain, memiliki seorang anak tidak membatasi seseorang untuk mampu menikmati fasilitas perpustakaan.

\section{e) Café Pustaka}

Café pustaka merupakan café atau food court tempat untuk mendapatkan makanan dan minuman. Seringkali aturan dari perpustakaan adalah melarang pengguna untuk membawa makanan ke dalam area perpustakaan. Jika pengguna ingin memanfaatkan fasilitas perpustakaan sehari penuh, maka akan sangat menyulitkan dengan adanya peraturan tersebut. Maka dari itu perpustakaan Universitas Negeri Malang menyediakan café pustaka, sehingga dengan adanya café tersebut, upaya perpustakaan dalam rangka memfasilitasi pengguna untuk berliterasi, belajar dan mengembangkan ide serta kreativitasnya dapat disediakan senyaman mungkin dengan adanya café tersebut, pemustaka juga terdorong datang ke perpustakaan karena dekat dengan tempat makan seperti café (hasil wawancara dengan Pak Kosasih, Pak Nurhakim, dan Endro Kurniawan).

\section{Perpustakaan Berbasis Inklusi Sosial}

Hasil wawancara dengan Prof. Djoko Saryono (Kepala Perpustakaan Universitas Negeri Malang), konsep dari perpustakaan inklusi adalah sebagai berikut:

"Ini dimaksudkan sebagai bentuk upaya perpustakaan yang bertanggung jawab untuk mengatasi pengucilan sosial misalnya etnis tertentu, orang cacat, orang berpenyakit tertentu melalui kebijakan pengembangan infrastruktur yang memungkinkan komunikasi informasi"

Pengelolaan yang berbasis inklusi sosial memadukan manajemen perpustakaan dan memanfaatkan pengembangan teknologi informasi, sehingga perpustakaan Universitas Negeri Malang mengembangkan berbagai layanan digital yang dapat diakses oleh masyarakat kapanpun dan dimanapun ia berada sebagai salah satu upaya mendukung perpustakaan inklusi. Dengan slogannya perpustakaan Universitas Negeri Malang yang ingin menerapkan "Library Follow Users".

Strategi perpustakaan Universitas Negeri Malang untuk mencapai tujuan berinklusi sosial adalah mengembangkan kerjasama antar perpustakaan, melalui beberapa macam media, seperti: 


\section{a) Sistem Informasi Pustaka Terpadu (SIPADU)}

SIPADU merupakan suatu layanan informasi perpustakaan yang bersifat terpadu, mengkoneksikan berbagai perpustakaan di tingkat fakultas-fakultas yang ada di Universitas Negeri Malang dengan perpustakaan pusat. SIPADU menggunakan sistem artificial intelligence untuk menggerakkan dan mengkoneksikan berbagai macam layanan sehingga menjadi satu kesatuan yang terhubung dalam satu koneksi, dengan menggunakan fasilitas yang disebut CDS/ISIS (Computerized Documentation Services/Integrated Set). SIPADU juga dapat digunakan sebagai media untuk peminjaman dan perpanjangan buku secara online, sehingga pengguna tidak perlu mencari-cari buku melalui perpustakaan secara offline dan cukup datang ke perpustakaan untuk langsung mengambil buku yang dipesan melalui online tersebut. Pengguna juga dapat melihat hak pinjam, lama peminjaman, lama perpanjangan, daftar buku yang sedang dipinjam, proses dipesan maupun yang pernah dipinjam.
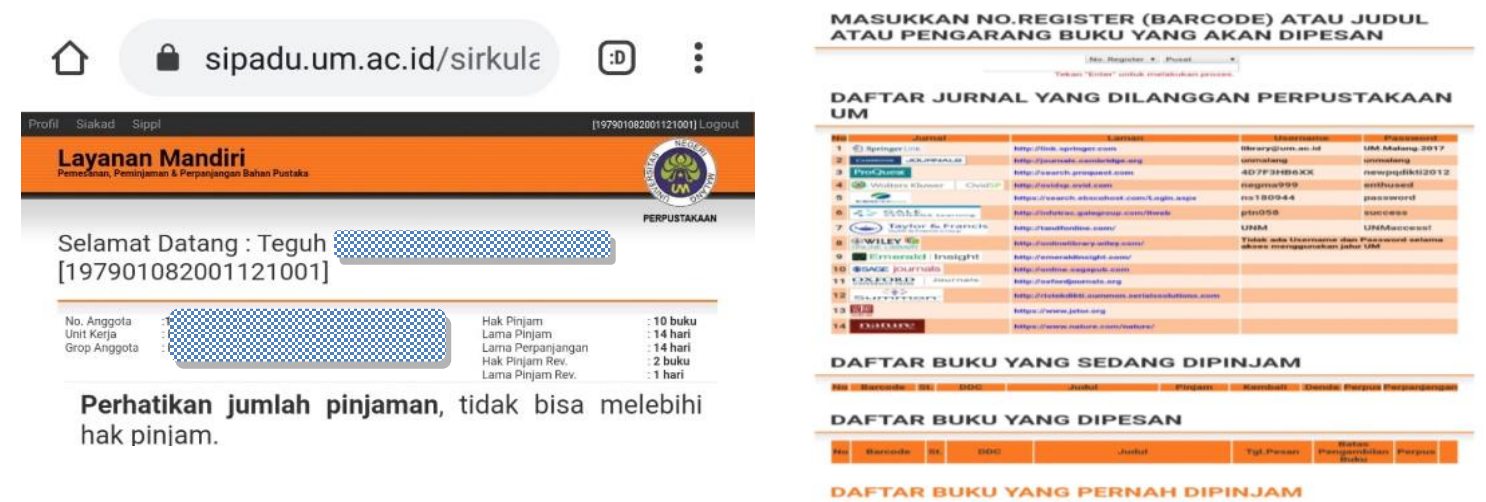

Gambar 2. Tampilan SIPADU untuk peminjaman buku secara online Sumber: https://SIPADU.um.ac.id/sirkulasi//

\section{b) Indonesia OneSearch}

Indonesia OneSearch merupakan aplikasi satu pintu untuk pencarian semua koleksi publik dari perpustakaan, museum, arsip dan sumber elektronik di Indonesia. Aplikasi ini digerakkan oleh Perpustakaan Nasional dan dapat diakses melalui alamat https://onesearch.id/. Universitas Negeri Malang telah membangun kolaborasi dengan Perpustakaan Nasional sebagai kontributor di Indonesia OneSearch. Hasil dari keterbukaan informasi tersebut membawa perpustakaan Universitas Negeri Malang menjadi kontributor utama ke-3 secara nasional untuk penyediaan koleksi publik.

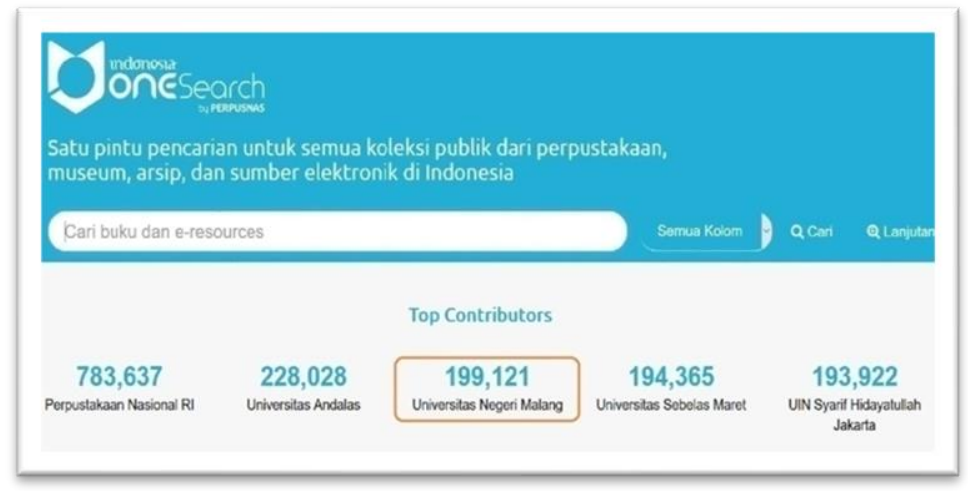

Gambar 3. Tampilan UM pada Indonesia OneSearch Sumber: https://onesearch.id/ 


\section{c) Layanan Chat Reference}

Layanan chat reference merupakan sebuah layanan cepat tanggap untuk merespons kebutuhan dan berinteraksi secara online dengan pemustaka. Latar belakangnya adalah pergeseran generasi pemustaka yang mampu beradaptasi terhadap teknologi secara cepat (digital experts) serta era mobile phone saat ini yang memposisikan telepon genggam sebagai kebutuhan primer. Sehingga perpustakaan Universitas Negeri Malang merealisasikan harapan pengguna layanan virtual yang barkarakter digital native di lingkungan online dengan mempertimbangkan prinsip aksesibilitas, kepercayaan, respons cepat, privasi, dan keterbukaan terhadap berbagai pertanyaan yang diberikan oleh pemustaka. Selain adanya latar belakang tersebut, layanan ini dimaksudkan juga sebagai penyedia layanan untuk penyandang disabilitas yang mengalami keterbatasan fisik untuk mengakses perpustakaan secara langsung. Manfaat yang didapatkan dari layanan ini adalah membantu masyarakat dengan beragam keadaan, baik itu jauh dari perpustakaan secara geografis maupun adanya keterbatasan fisik sehingga cukup menyulitkan untuk dapat berkunjung ke perpustakaan. Selain itu dalam rangka memanfaatkan teknologi informasi sehingga mampu menjembatani kesenjangan/ keterbatasan fasilitas yang dimiliki perpustakaan.

Layanan Chat Reference dapat diakses melalui facebook (https://www.facebook.com/pages/Perpustakaan-Universitas-Malang/), Instagram (https://www.instagram.com/perpustakaan.um/),

Twitter (https://twitter.com/Perpustakaan UM). Selain itu, ada aplikasi Let's Talk pada website perpustakaan Universitas Negeri Malang.
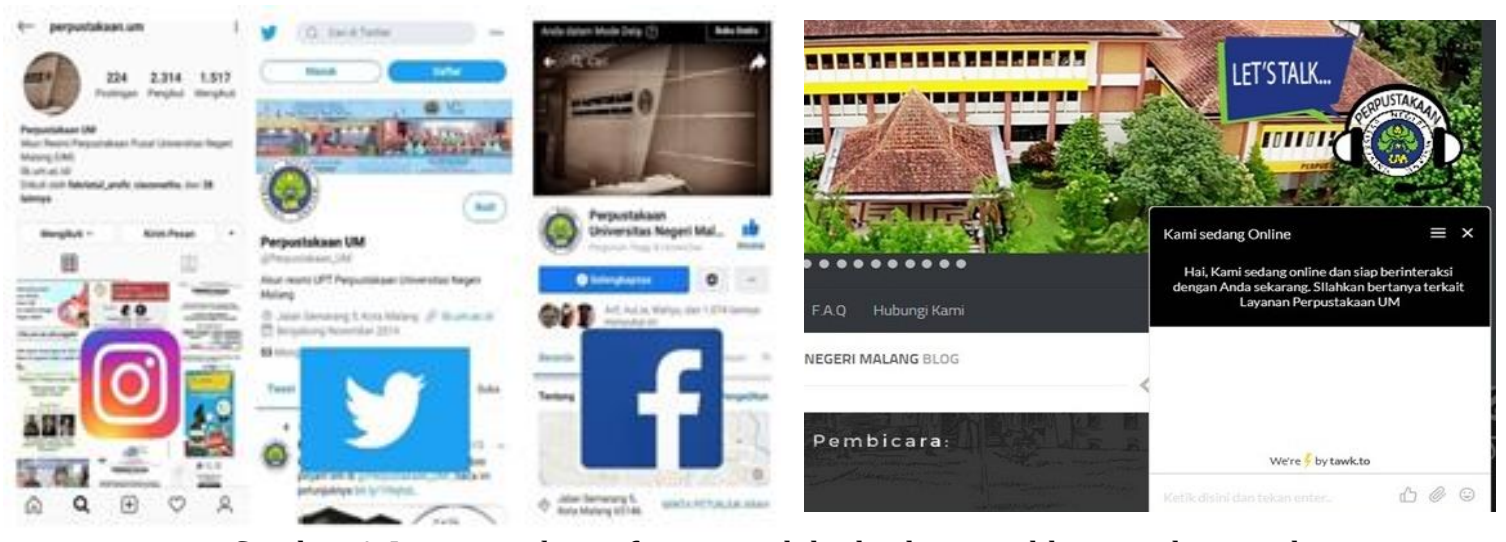

Gambar 4. Layanan chat reference melalui berbagai aplikasi media sosial

Sumber: https://lib.um.ac.id

\section{d) Media Streaming (pada aplikasi media sosial)}

Media streaming dimaksudkan untuk menampilkan berbagai kegiatan yang dilaksanakan oleh perpustakaan Universitas Negeri Malang seperti seminar, diskusi umum, bedah buku dan pertunjukan seni dapat dibuat sebagai konten yang ditampilkan pada akun media sosial perpustakaan Universitas Negeri Malang. Media streaming ini adalah sebuah fitur streaming secara online yang berisi konten-konten video pada aplikasi Facebook, Instagram dan YouTube.

Salah satu tujuan dari media streaming ini adalah agar pemustaka yang tidak dapat mengikuti suatu kegiatan (diskusi/seminar/workshop) karena keterbatasan fisik/jarak akan tetap mendapatkan pengetahuan/informasi dari kegiatan yang dilaksanakan meskipun tidak hadir secara langsung di perpustakaan dengan mengakses media sosial perpustakaan.

\section{e) Literasi Informasi}

Literasi informasi merupakan sarana dan pendidikan literasi yang diperuntukkan untuk pustakawan, dan seluruh warga sivitas akademika. Literasi informasi ini dilatarbelakangi oleh pengguna terbanyak perpustakaan perguruan tinggi yang saat ini didominasi oleh generasi digital native. Generasi digital native lebih banyak mengisi kehidupan dengan penggunaan 
komputer, smartphone dan berbagai macam perangkat yang diproduksi di abad digital. Di era digital native tersebut, pengetahuan dan skill dasar yang harus dimiliki adalah kemampuan literasi (literasi informasi, media, dan teknologi).

Dengan tujuan itu, perpustakaan Universitas Negeri Malang memberikan fasilitas pendidikan dan informasi kepada seluruh pustakawan dan sivitas akademika melalui berbagai macam cara yaitu sebagai berikut: (a) Kegiatan orientasi perpustakaan Universitas Negeri Malang yang dilaksanakan setiap tahun, (b) Pembekalan keterampilan literasi informasi dalam menunjang pembelajaran sepenjang hayat. (c) Program Kelas Literasi bagi mahasiswa Universitas Negeri Malang.

Jika dikaitkan dengan indikator pelayanan Library 4.0 menurut Noh (2015), Shaleh (2005) dan Maryani (2016) inovasi-inovasi tersebut mampu mendorong terciptanya Library 4.0 seperti pada tabel berikut:

Tabel 1. Klasifikasi inovasi layanan Perpustakaan UM dibandingkan dengan indikator Library 4.0

\begin{tabular}{|c|c|c|}
\hline \multicolumn{2}{|c|}{ Aspek Pelayanan Perpustakaan era 4.0} & \multirow{2}{*}{$\begin{array}{l}\text { Inovasi Pelayanan Perpustakaan } \\
\text { UM }\end{array}$} \\
\hline $\begin{array}{l}\text { Intelligence } \\
\text { makerspace }\end{array}$ & $\begin{array}{l}\text { Perpustakaan menyediakan tempat yang } \\
\text { nyaman, fasilitas yang memadai sesuai } \\
\text { dengan kebutuhan pemustaka (learning } \\
\text { commons) }\end{array}$ & \\
\hline Open Source & $\begin{array}{l}\text { Menyediakan koleksi online dan mobile } \\
\text { library }\end{array}$ & $\begin{array}{l}\text { SIPADU, Indonesia OneSearch, Kebun } \\
\text { E-book }\end{array}$ \\
\hline Big data & $\begin{array}{l}\text { Pengelolaan data melalui media online } \\
\text { bersifat terpadu (one stop searching) }\end{array}$ & SIPADU \\
\hline $\begin{array}{l}\text { Cloud } \\
\text { Computing }\end{array}$ & Segala aktivitas dijalankan secara online & $\begin{array}{l}\text { SIPADU, Layanan chat reference } \\
\text { (Facebook, Twitter, Let's Talk) }\end{array}$ \\
\hline \multirow{3}{*}{$\begin{array}{l}\text { Augmented } \\
\text { Reality }\end{array}$} & Penyediaan katalog online secara lengkap & Website perpustakaan UM, SIPADU, \\
\hline & $\begin{array}{l}\text { Sumber informasi kilat dan references } \\
\text { Pelayanan berbasis web interaktif antara } \\
\text { pemustaka dan pustakawan }\end{array}$ & $\begin{array}{l}\text { Layanan Chat reference (Facebook, } \\
\text { Twitter, Let's Talk) }\end{array}$ \\
\hline & $\begin{array}{l}\text { Penyediaan pinjaman buku dan } \\
\text { perpanjangan buku secara online }\end{array}$ & \\
\hline State of Art & Pengembangan layanan yang selalu baru & $\begin{array}{l}\text { Pentas Seni, Bazar Buku, Lapak } \\
\text { Diskusi, Movie talk, dll }\end{array}$ \\
\hline Librarians 4.0 & $\begin{array}{l}\text { Pustakawan mampu meng-upgrade } \\
\text { kemampuan kepustakaan melalui media } \\
\text { online }\end{array}$ & Program Literasi Pustakawan \\
\hline
\end{tabular}

Hasil wawancara ditemukan bahwa faktor terbesar dari keberhasilan pengadaan inovasi tersebut adalah adanya sumber daya manusia (pegawai, personil) yang kreatif didukung dengan peningkatan jenjang pendidikan yang mapan (dipermudahnya melanjutkan studi bagi pustakawan, pelatihan-pelatihan), serta tekad dan komitmen dari setiap anggota pustakawan perpustakaan Universitas Negeri Malang untuk menerapkan program inovasi dengan optimal.

"Pimpinan kami, Prof. Djoko Saryono betul-betul memberikan arahan kepada staf manajemen perpustakaan Universitas Negeri Malang untuk merubah mindset dari menunggu pengguna perpustakaan ke menjemput pengunjung dengan melakukan inovasi terhadap sumber daya yang ada" (Nurhakim, Staf Pengadaan).

Respons dari staf lain menyatakan motivasi mereka dalam berinovasi, adalah sebagai berikut:

"Kami itu sudah mendapatkan fasilitas yang beragam secara gratis sebagai pegawai perpustakaan, mau melanjutkan sekolah ya disekolahkan, kita juga terus diberi pelatihan, sayang kalau ada ketimpangan. Kita tahu sendiri mahasiswa Universitas Negeri Malang itu beragam, ada yang kaya ada yang tidak mampu, untuk beli buku saja susah, apalagi berlangganan jurnal, makanya kami terus memikirkan cara bagaimana memudahkan 
mereka mengakses buku, muncullah inovasi seperti Kebun E-book contohnya, jadi kami sudah seperti kesadaran sendiri untuk terus melakukan inovasi dari berbagai masalah di lapangan" (Staf Pengelolaan Data Kebun E-book).

Usaha-usaha yang dilakukan oleh perpustakaan Universitas Negeri Malang untuk menciptakan komitmen sumber daya manusia agar selalu berinovasi adalah menciptakan kesadaran kepada masing-masing pustakawan bahwa tugas pustakawan begitu urgent untuk menyediakan dan memudahkan pembelajar agar mendapatkan ilmu pengetahuan yang dibutuhkan. Motivasi dari pustakawan untuk berinovasi adalah, perpustakaan harus dapat menjembatani gap antara motivasi belajar dengan keterbatasan sumber daya. Walaupun banyak pelajar yang tidak mampu secara ekonomi untuk membeli buku terutama buku import, atau memiliki keterbatasan fisik untuk belajar, dengan motivasi belajar yang tinggi, harusnya perpustakaan mampu menjawab keterbatasan pemustaka yang ada di lapangan, sehingga perpustakaan memiliki nilai manfaat yang sangat besar.

Meskipun begitu tidak dielakkan sebuah sistem tidak akan berjalan langsung secara sempurna. Meskipun perpustakaan Universitas Universitas Negeri Malang telah berupaya memenuhi standar layanan library 4.0, beberapa poin indikator library 4.0 belum dijalankan secara maksimal, seperti penyediaan peminjaman buku, pemustaka dapat meminjam secara online, namun tidak ada fasilitas pengiriman ke tempat pemustaka, pemustaka harus tetap mengambil buku yang dipinjam secara offline dengan datang ke perpustakaan. Selain itu juga dari aspek librarian 4.0, pustakawan belum mampu menerapkan sepenuhnya, belum ada sistem pelatihan-pelatihan melalui online, belum ada kebijakan terkait kewajiban pustakawan mengikuti grup-grup pelatihan online dan masih rendahnya peran pustakawan dalam publikasi online. Salah satu faktor penghambat dari tidak diterapkannya layanan pengiriman pinjaman online tersebut adalah terbatasnya sumber daya manusia pustakawan, belum tersedia sumber daya manusia yang dapat fokus dalam hal itu, dan juga faktor sistem pembiayaan pengiriman online yang belum tersedia. Hal itu senada dengan salah satu artikel yang ditulis oleh Novianto (2018), yang mengatakan bahwa hambatan dari kinerja perpustakaan Universitas Negeri Malang adalah kurangnya sumber daya manusia pustakawan yang dimiliki.

\section{DISKUSI}

Berdarkan hasil dari penelitian tersebut, inovasi eco-blended library merupakan inovasi baru yang termasuk dalam kategori penambahan fasilitas baru (addition) dan wujud dari penguatan (reinforcement) program yang sebelumnya sudah terlaksana. Kemudian dikembangkan menjadi sebuah inovasi yang perubahannya bersifat incremental (perlahanperlahan dan berproses). Banyak perpustakaan yang telah mencoba menerapkan konsep yang sama, mulai dari inklusi sosial dan pelayanan digital, namun hal yang membedakan inovasi dari perpustakaan berbasis inklusi sosial yang diterapkan oleh perpustakaan Universitas Negeri Malang ini adalah dari segi caranya yang baru. Seperti dalam hal pemanfaatan digital library, perpustakaan Universitas Negeri Malang sudah menerapkan konsep big data, yaitu pengelolaan perpustakaan terpadu. Universitas Negeri Malang mampu mengkoneksikan seluruh jaringan perpustakaan mulai dari lingkup fakultas hingga pusat dan segala macam pelayanan perpustakaan dalam satu perangkat online yakni SIPADU. Kemudian adanya fasilitas fast respon dalam komunikasi secara online antara pemustaka melalui sosial media Facebook, Instagram, Twitter hingga Lets Talk melalui website perpustakaan Universitas Negeri Malang juga merupakan keberhasilan inovasi.

Ketika terbentuk sebuah inovasi, seringkali hanya menjadi sebuah wacana yang bagus namun sangat buruk dalam pelaksanaan bahkan tidak terlaksana secara berkelanjutan, hal itu disebabkan oleh beberapa faktor yaitu budaya sulit berubah dari sumber daya manusia pada umumnya dan pelayan publik pada khususnya. Berdasarkan penelitian, sumber daya manusia seringkali mengalami resistensi terhadap perubahan dari organisasinya (Lewin, 1947). Penelitian terdahulu menyebutkan salah satu hambatan inovasi ketika diterapkan adalah dari faktor kompetisi dan motivasi sumber daya manusia (Nashihuddin, 2018). Menurut survei yang dilakukan oleh Society for Human Resource Management (SHRM) pada Tahun 2003, resistansi 
merupakan satu dari dua faktor tertinggi penyebab kegagalan dalam perubahan maupun terhambatnya perubahan, dengan kata lain lawan dari resistensi atau komitmen dari sumber daya manusia atas inovasi adalah faktor utama penentu keberhasilan inovasi.

Salah satu upaya yang dilakukan perpustakaan Universitas Negeri Malang agar inovasi berjalan secara kontinu adalah, dengan melakukan inovasi yang bersifat incremental. Banyak fasilitas yang diterapkan secara bertahap dan kemudian menjadi perubahan yang cukup fundamental. Selain itu untuk menggerakkan suatu inovasi di pelayanan publik, diperlukan adanya kesadaran dari setiap anggota untuk memberikan nilai manfaat kepada masyarakat luas. Perlu menciptakan kesadaran kepada sumber daya manusia bahwa keberadaannya dalam suatu organisasi (dalam hal ini adalah perpustakaan), dibutuhkan untuk mensukseskan suatu tujuan yang besar. Dan dibutuhkan oleh banyak orang yang memiliki keterbatasan untuk meraih tujuan tersebut. Maka dari itu dengan sendirinya komitmen dari sumber daya manusia akan semakin tinggi untuk menciptakan sebuah terobosan-terobosan dalam pelayanan publik termasuk dalam menggerakkan perpustakaan, sehingga keberadaan perpustakaan tidak akan mati dan semakin dibutuhkan di era industri 4.0.

\section{KESIMPULAN}

Perpustakaan Universitas Negeri Malang sebagai sebagai pusat rujukan dan informasi ilmiah (Information Center and Center of Knowledge Access) telah berhasil menerapkan inovasiinovasi berupa program eco-blended library seperti Kebun E-book, Beringin Baca, playground anak-anak, café pustaka, pentas seni, movie talk, lapak diskusi, tempat ibadah (musala). Selain itu juga mampu mengembangkan perpustakaan berbasis inklusi dengan adanya fasilitas SIPADU, digitalisasi koleksi bekerjasama dengan Indonesia OneSearch, layanan chat reference, peminjaman dan perpanjangan online, serta literasi informasi. Berbagai macam informasi tersebut sesuai dengan indikator layanan Library 4.0 seperti intelligence makerspace, open source, big data, cloud computing, augmented reality, state of art, dan librarian 4.0. Keadaan seperti itu didukung oleh adanya kreativitas dan dukungan yang kuat akan edukasi pustakawan serta komitmen yang kuat sumber daya manusia pustakawan Universitas Negeri Malang dalam melaksanakan inovasi, dan beberapa penghambat dari adanya pelayanan berbasis 4.0 adalah kurangnya sumber daya manusia pustakawan yang dimiliki oleh Universitas Negeri Malang. Sehingga saran untuk perpustakaan Universitas Negeri Malang adalah meningkatkan jumlah sumber daya manusia yang fokus dalam layanan digital library, semakin mendorong sumber daya manusia untuk melakukan publikasi ilmiah online dan mengikuti forum/grup-grup pelatihan online. Bagi perpustakaan lain, upaya inovasi bertahap (incremental) dan bersifat kontinu yang diterapkan oleh perpustakaan Universitas Negeri Malang dapat digunakan sebagai benchmark pengembangan layanan perpustakaan dengan ekosistem library 4.0.

\section{DAFTAR PUSTAKA}

Cresswell, J. W. (2010). Research Design Pendekatan Kualitatif, Kuantitatif, dan Mixed Edisi ketiga. In Yogyakarta: Pustaka Pelajar.

Cribb, G. (2018). Great exaggerations! Death of Libraries. Retrieved from https://blogs.ifla.org/arl/2018/01/25/great-exaggerations-death-of-libraries/

Erawati Djamrut, D. (2015). Inovasi Pelayanan Publik di Kecamatan Sungai Kunjang Kota Samarinda. Ejournal Ilmu Pemerintahan, 3(3), 1472-1486.

Gavin, R. (2005). Classroom Approaches for Assessment, and Learning. London: Fulton Publisher.

Goetsch, David L., and Davis B. Stanley. (2000). Quality Management: Introduction to Total Quality Management for Production, Processing, and Services, Third Edition, PrenticeHall, Inc., New Jersey.

Hauke, P. (2015). How to become / how to identify a green Library? standards for certification. IFLA WLIC 2015. 
Hauke, P., Grunwald, M., \& Wilde, A. (2014). Green Libraries Coming Up! National and international initiatives fostering enviromental sustainable libraries and library services. BOBCATSSS 2014.

Herviani, Vivi Kurnia. Dkk. 2018. Evaluasi Peserta Didik Sekolah Penyelenggara Pendidikan Inklusif Di Kota Bontang, Jurnal Pendidikan Inklusi, 1(1), 146-153

Hidayah, Kemal \& Kusumaningrum, Mayahayati \& Heru Wismono, Fani \& Amarullah, Rustan. (2018). Aktualisasi Budaya Inovasi Pada Organisasi Sektor Publik. Jurnal Borneo Administrator. 14. 249-266.

Ibrahim. (1988). Inovasi Pendidikan. Jakarta: Proyek Pengembangan Lembaga Pendidikan Tenaga Kependidikan, Ditjen Dikti Depdikbud

Istiana, Purwani. (2016). Gaya belajar dan perilaku digital native terhadap teknologi digital dan perpustakaan. In: SLiMS Commeet West Java 2016 "Senayan Library Management System Community Meet Up West Java., 17 Desember 2016, Universitas Pendidikan Bandung

Jalil, A., Beer, M., Crowther, P. (2015). Pedagogical Requirements for Mobile Learning: A Review on MOBIlearn Task Model. Journal of Interactive Media in Education, 12, pp. 1-17, DOI: http://dx.doi.org/10.5334/jime.ap. Kemendikbud

Maryani, Eri. (2016). Peningkatan Kualitas Pelayanan Perpustakaan Untuk Digital Native Generation (Perspektif Perubahan Karakter Pemustaka Di Era Digital). Prosiding Seminar Nasional Komunikasi 2016.

Meher, P., \& Parabhoi, L. (2017). Green Library: An overview, issues with special reference to Indian libraries. International Journal of Digital library Services, 7(2), 62-69.

Miles, M.B, Huberman, A.M, \& Saldana, J. (2014). Qualitative Data Analysis, A. Methods Sourcebook, Edition 3. USA: Sage Publications. Terjemahan.

Mulgan, Geoff and David Albury. (2003). Innovation in the Public Sector. Strategy Unit, Cabinet Office.

Nashihuddin, W., Suryono, F. (2018). Tinjauan terhadap Kesiapan Pustakawan dalam Menghadapi Distrupsi Profesi di Era Library 4.0: Sebuah Literatur Review. Khizanah alHikmah : Jurnal Ilmu Perpustakaan, Informasi, dan Kearsipan. 6(2), 86-97

Noh, Y. (2015). Imagining Library 4.0: Creating a Model for Future Libraries. The Journal of Academic Librarianship.http://dx.doi.org/10.101 6/j.acalib.2015.08.020.

Noor, M. U. (2019). Aplikasi Layanan Informasi Berbasis Internet untuk Menumbuhkan Inklusi Sosial di Perpustakaan Daerah. JIPI (Jurnal Ilmu Perpustakaan dan Informasi), 4(1), 8495.

Novianto, Achmad Qorni. (2019). Analisis Sebaran Butir Kegiatan Pustakawan Berdasarkan Permenpan-Rb Nomor 9 Tahun 2014. Baca: Jurnal Dokumentasi Dan Informasi.

NS, S. (2008). Membina Perpustakaan Desa. Jakarta: Sagung Seto.

Olsen, G. \& Fuller, M. 2003. Home School Relation. Working Successfully with Parents and Families. Boston: Allyn and Bacon.

Osborne, Stephen P. (2002). Voluntary Organizations and Innovation in Public Services. Taylor \& Francis e-Library.

Rhoni, R. (2019). Analisis Kesiapan dan Tantangan Perpustakaan Perguruan Tinggi Islam di Indonesia Menghadapi Era 4.0. Media Pustakawan, 26(2), 81-90.

Rodhin, R. M. (2019). Arah Kebijakan Pengembangan Perpustakaan IAIN CURUP Menghadapi Era Industri 4.0. Al-Makatabah, 4(1), 14-24.

Robbins, Stephen P., (1994). Teori Organisasi: Struktur, Desain dan Aplikasi, Alih Bahasa Jusuf Udaya, Jakarta, Arcan

Sari, E. A. (2019). Peran Pustakawan AI (Artificial Intelligent) Sebagai Strategi Promosi Perpustakaan Perguruan Tinggi Di Era Revolusi 4.0. Bibliotika: Jurnal Kajian Perpustakaan Dan Informasi, 3(1), 64-73.

Shabarudin, (2017), Makalah Seminar Nasional: Meningkatlkann Peran Perpustakaan Era Digital Dalam Dinamika Generasi Millenea, Di Unversitas Barwijaya, Fakuktas Ilmuadministrasi, Malang

Shaleh, A. Rahman. (2005). Pendayagunaan Layanan Perpustakaan Berbasis Teknologi Informasi. Jurnal Pustakawan Indonesia. Vol. 4 no 2 
Suwarno, Yogi. (2008). Inovasi di Sektor Publik. Jakarta: STIA LAN.

Zeithaml, V. A., Parasuraman, A., Berry, L. L., \& Berry, L. L. (1990). Delivering quality service: Balancing customer perceptions and expectations. Simon and Schuster. 